\title{
Systemic Racism in Police Killings: New Evidence From the Mapping Police Violence Database, 20|3-202|
}

\section{Reed T. DeAngelis ${ }^{1,2}$ ii}

\begin{abstract}
This research note provides new evidence consistent with systemic anti-Black racism in police killings across the United States. Data come from the Mapping Police Violence Database (2013-202I). I calculate race-specific odds and probabilities that victims of police killings exhibited mental illness, were armed with a weapon, or attempted to flee the scene at the time of their killing. Multilevel, multivariable logistic regression techniques are applied to further account for the victim's age, gender, year of killing, and geographical clustering. I find that White victims are underrepresented, and Black victims overrepresented in the database. Relative to White victims, Black victims also have $60 \%$ lower odds of exhibiting signs of mental illness, $23 \%$ lower odds of being armed, and $28 \%$ higher odds of fleeing. Hispanic victims exhibit $45 \%$ lower odds of being armed relative to their White peers but are otherwise comparable. These patterns persist regardless of the victim's age, gender, year of killing, or geographical location (state, zip code, and neighborhood type). Thus, the threshold for being perceived as dangerous, and thereby falling victim to lethal police force, appears to be higher for White civilians relative to their Black or Hispanic peers. Current findings provide empirical support for political initiatives to curb lethal police force, as such efforts could help to reduce racial disparities in deaths by police nationwide.
\end{abstract}

\footnotetext{
'Department of Sociology, University of North Carolina at Chapel Hill, Chapel Hill, NC, USA

${ }^{2}$ Carolina Population Center, Chapel Hill, NC, USA
}

\section{Corresponding Author:}

Reed T. DeAngelis, Department of Sociology, 155 Pauli Murray Hall, CB \#3210, UNC-CH, Chapel Hill, NC 27599-3210, USA.

Email: reedd@live.unc.edu 


\section{Keywords}

deadly force, fatal police encounters, Mapping Police Violence Database, systemic racism

\section{Introduction}

Recent high-profile police killings of Persons of Color (POC) across the United States (US) continue to spark debates and protests about the enduring presence of systemic racism in policing. Systemic racism refers to stereotypes, emotions, and practices that are reproduced across time and place to advantage one racialized group over others (Phelan \& Link, 2015). Charges of systemic racism in policing reflect a broader discourse on continuing legacies of structural and institutional racism in the United States, or how major US institutions-including the criminal justice system, banks, and hospitals, among others-have been established over time to benefit White communities at the expense of minoritized communities (Gee \& Hicken, 2021; Rothstein, 2017).

These charges are not unfounded. It is now well-established that policing in the United States is tainted by a deeply racist, anti-Black legacy (Alexander, 2010; Gruber, 2021). Aside from its racist inception, the policing profession continues to struggle with diversity issues, as police forces across the United States are still dominated by White men (Ba et al., 2021; Morabito \& Shelley, 2015). Lack of diversity among police jurisdictions, in turn, can perpetuate an unempathetic, "us versus them" standpoint toward communities of color (Legewie \& Fagan, 2016), whereby POC civilians are more easily dehumanized than their White peers (Van Cleve, 2016). Moreover, dominant police training tactics can further distort officers' perceptions of on-the-job hazards. For example, police training narratives commonly depict routine traffic stops as perilous encounters that command hyper-vigilance of officers, despite recent estimates indicating that only 1 in 6.5 million traffic stops result in the killing of a police officer (Woods, 2019).

All these factors lead to the reasonable expectation that police officers will tend to be racially biased in their use of lethal force. However, although POC are known to be overrepresented among police killings relative to White persons (Sinyangwe et al., 2021), the reasons for these apparent racial disparities remain obscured. One key source of ambiguity lies in how courts and police jurisdictions have chosen to define "reasonableness" in the use of lethal force. Courts have authorized police officers to use lethal force whenever they perceive "probable cause" that a suspect poses a physical threat. However, without setting objective criteria for "reasonableness" or "probable cause," courts have empowered police officers to act on split-second reasoning that can become clouded by momentary stressors and personal biases (Fagan \& Campbell, 2020).

The aim of this research note is to provide new evidence of systemic racism in police killings across the United States with updated data from the Mapping Police Violence Database (MPVD; 2013-2021). The MPVD includes information about multiple 
types of police killings, by both on- and off-duty police officers; the race of the victim; whether the victim exhibited signs of mental illness, was armed, or attempted to flee in the moments leading up to their killing; as well as the zip code, state, and neighborhood type — urban, suburban, or rural —in which each killing took place. With these data, I can test multivariable, multilevel models that account for geographic clustering of fatal police encounters nested within zip codes and states. This strategy allows me to reveal potential racial biases in officers' perceptions of "probable cause" of threat, even after accounting for other victim traits and nationwide geographical heterogeneity.

To be sure, other recent studies have found that police officers-especially White officers-are significantly more likely to kill Black and Hispanic civilians, relative to their White peers, even when civilians are unarmed and do not exhibit mental illness (Ba et al., 2021; Fagan \& Campbell, 2020; Legewie \& Fagan, 2016; Thomas et al., 2021). But these studies were either limited to certain regions like Chicago, or they used older data from the Washington Post that only included fatal shootings by on-duty police officers between 2013 and 2018-2019. The present study uses updated data that includes multiple types of killings, by both on- and off-duty officers, between 2013 and 2021, and across numerous zip codes and states. With the current data and analytic techniques, I can more rigorously document systemic racism in police killings nationwide.

\section{Methods}

The MPVD currently represents one of the most comprehensive databases of police killing victims in the United States (Sinyangwe et al., 2021). Documented fatal encounters include deaths by shooting, chokehold, baton, taser, or other means by on- and off-duty police officers between January 2013 and March 2021. The database also includes information about the victim's race, age, gender, geographic location, and behaviors leading up to their fatal police encounter. My final analytic sample includes Black, Hispanic, and White victims of police killings $(N=7,675)$. I exclude Asian and Native American victims due to small cell sizes, as well as victims for whom race was not documented.

The three main outcomes are dichotomous and include whether the victim: (1) exhibited signs of mental illness at the scene, (2) was armed at the scene, or (3) attempted to flee the scene by foot or vehicle $(1=$ yes, $0=$ no). Multilevel logistic regression techniques are used to calculate race-specific odds and marginal probabilities of exhibiting each behavior, adjusting for random intercepts by state and zip code; the victim's age (in years) and gender (male vs. female); and the year and geography (urban, suburban, rural) of the encounter. This strategy can determine whether racial disparities in police victimology persist net of other victim traits and average differences across geographic clusters (Raudenbush \& Bryk, 2002).

All statistical analyses are conducted in Stata 14. I use Stata's melogit command to calculate multilevel, binary logistic regression estimates with random intercepts for fatal encounters nested within zip codes, nested within states. Missing data are handled with listwise deletion. 


\section{Results}

Table 1 provides descriptive statistics of study variables. In terms of victim behaviors, $26 \%$ exhibited signs of mental illness, $78 \%$ were armed at the scene, and $31 \%$ attempted to flee the scene. The average age of victims is 36 with a range of 1 to 107. The vast majority (95\%) of victims are male and the plurality $(50 \%)$ of encounters occur within suburban areas, followed by urban $(28 \%)$ and rural $(22 \%)$ areas. Finally, $51 \%$ of victims are documented as White, $29 \%$ are Black, and $20 \%$ are Hispanic. According to estimates from the 2020 US Census, $62 \%$ of the US population is non-Hispanic White, $12 \%$ is non-Hispanic Black, and $19 \%$ is Hispanic (US Census Bureau, 2021). Thus, White victims appear to be underrepresented, and Black victims overrepresented, in the MPVD dataset.

Table 2 provides odds ratios (OR), 95\% confidence intervals, and significance thresholds from multilevel binary logit estimates. ORs greater than one represent a positive association, while ORs less than one represent a negative association with each behavioral outcome. For example, between 2013 and 2021, the odds of victims

Table I. Descriptive statistics of study variables: mapping police violence database, 20I3-202I.

\begin{tabular}{|c|c|c|c|c|c|}
\hline & Mean & $S D$ & Min. & Max. & $N$ \\
\hline \multicolumn{6}{|c|}{ Victim exhibited mental illness } \\
\hline No (reference) & .74 & & 0 & I & 4,904 \\
\hline Yes & .26 & & 0 & I & $\mathrm{I}, 707$ \\
\hline \multicolumn{6}{|l|}{ Victim armed at the scene } \\
\hline No (reference) & .22 & & 0 & I & $\mathrm{I}, 703$ \\
\hline Yes & .78 & & 0 & 1 & 5,972 \\
\hline \multicolumn{6}{|l|}{ Victim attempted to flee } \\
\hline No (reference) & .69 & & 0 & 1 & 3,603 \\
\hline Yes & .31 & & 0 & 1 & 1,596 \\
\hline Year of encounter & 3.52 & 2.28 & 0 & 8 & 7,675 \\
\hline Age of victim & 36.34 & 12.87 & 1 & 107 & 7,561 \\
\hline \multicolumn{6}{|l|}{ Gender of victim } \\
\hline Female (reference) & .05 & & 0 & I & 387 \\
\hline Male & .95 & & 0 & I & 7,275 \\
\hline \multicolumn{6}{|l|}{ Geography of encounter } \\
\hline Suburban (reference) & .50 & & 0 & I & 3,800 \\
\hline Urban & .28 & & 0 & I & 2,141 \\
\hline Rural & .22 & & 0 & I & $|, 67|$ \\
\hline \multicolumn{6}{|l|}{ Race of victim } \\
\hline White (reference) & .51 & & 0 & I & 3,899 \\
\hline Black & .29 & & 0 & I & 2,240 \\
\hline Hispanic & .20 & & 0 & I & 1,536 \\
\hline
\end{tabular}

Notes: $S D=$ standard deviation. Min. $=$ minimum. Max. $=$ maximum. $N=$ observations for each variable or cell. Year of encounter ranges from $2013(=0)$ to $2021(=8)$. 


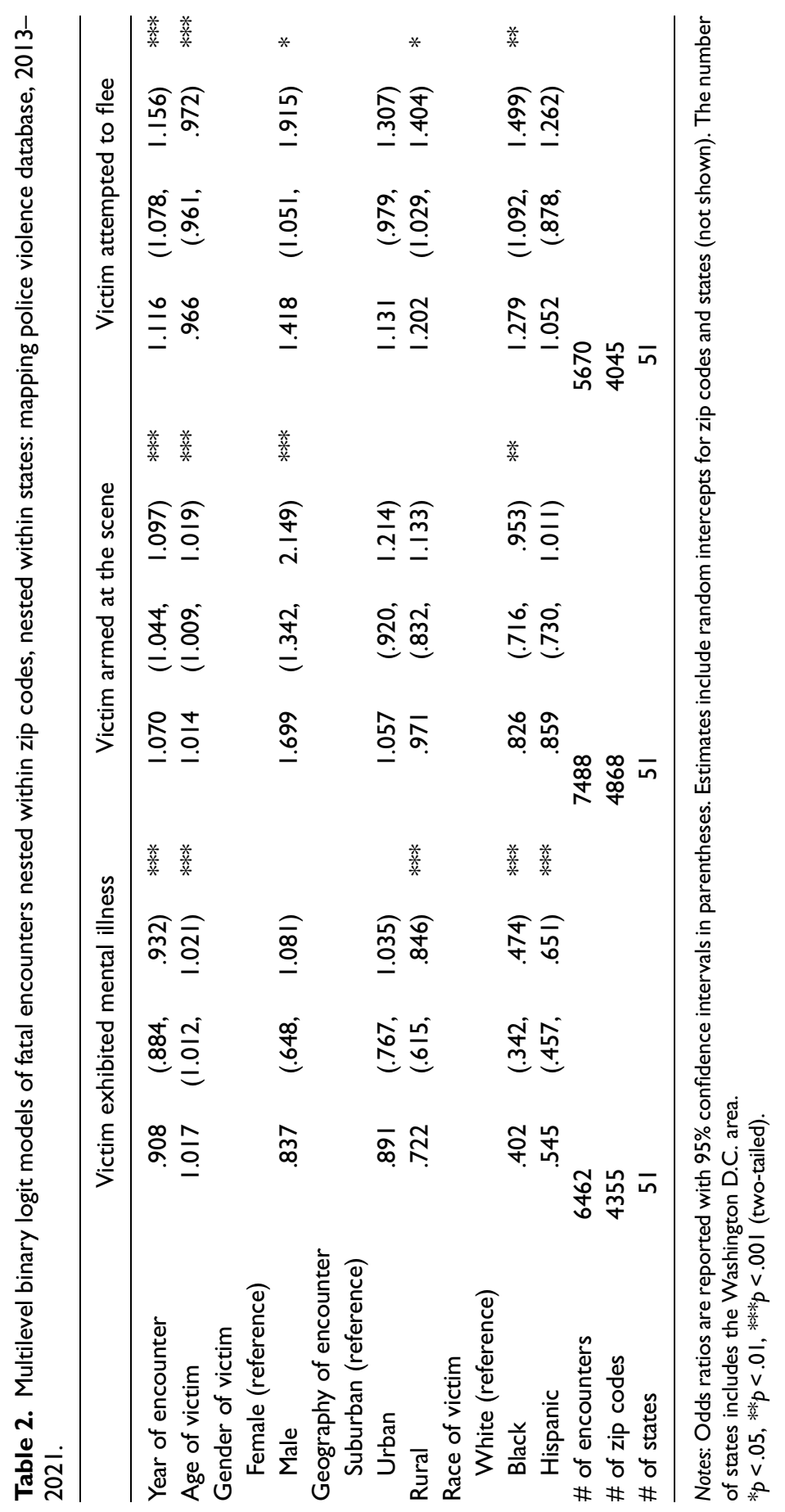


exhibiting signs of mental illness during encounters have declined by around $10 \%$ each year $(\mathrm{OR}=.908 ; p<.001)$. Conversely, odds of victims being armed $(\mathrm{OR}=1.070)$ or fleeing the scene $(\mathrm{OR}=1.116)$ have increased each year $(p<.001)$. The age of the victim is also a significant predictor of each outcome $(p<.001)$. Older age predicts greater odds of exhibiting mental illness $(\mathrm{OR}=1.017)$ and being armed at the scene $(\mathrm{OR}=1.014)$, but lower odds of fleeing the scene $(\mathrm{OR}=.966)$. Relative to female victims, male victims also have significantly greater odds of being armed $(\mathrm{OR}=$ $1.699 ; p<.001)$ and fleeing the scene $(\mathrm{OR}=1.418 ; p<.05)$.

The bottom of Table 2 displays coefficients by race. Relative to their White peers, Black victims have $60 \%$ lower odds of exhibiting mental illness (OR $=.402 ; p<.001)$, $17 \%$ lower odds of being armed at the scene $(\mathrm{OR}=.826 ; p<.01)$, but $28 \%$ greater odds of fleeing the scene $(\mathrm{OR}=1.279 ; p<.01)$. Hispanic victims also have $45 \%$ lower odds of exhibiting mental illness relative to Whites $(\mathrm{OR}=.545 ; p<.001)$, but otherwise are comparable. When comparing Hispanic and Black victims, Hispanic victims have $35 \%$ greater odds of exhibiting mental illness $(p<.01), 18 \%$ lower odds of fleeing the scene $(p<.05)$, but similar odds of being armed (not shown). These racial patterns hold regardless of the year of the encounter, age of victim, gender of victim, and the geographical clustering of encounters.

Figures 1 through 3 plot racial differences in behaviors as average marginal probabilities, with covariates held at their respective means. Figure 1 shows that White victims have a $32 \%$ predicted probability of exhibiting mental illness, while Black and Hispanic victims have respective probabilities of $16 \%$ and $21 \%$. In Figure 2,

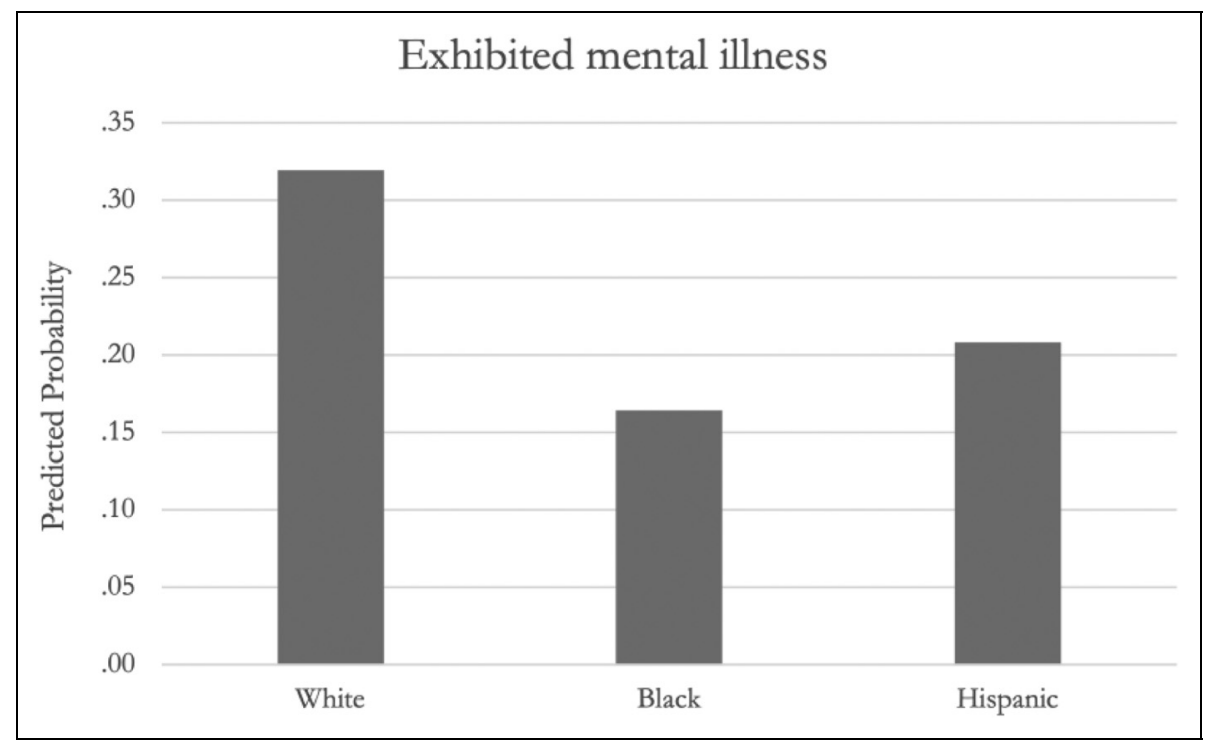

Figure I. Race-specific marginal probabilities of victims exhibiting mental illness during fatal police encounters: mapping police violence database, 20I3-2021. 


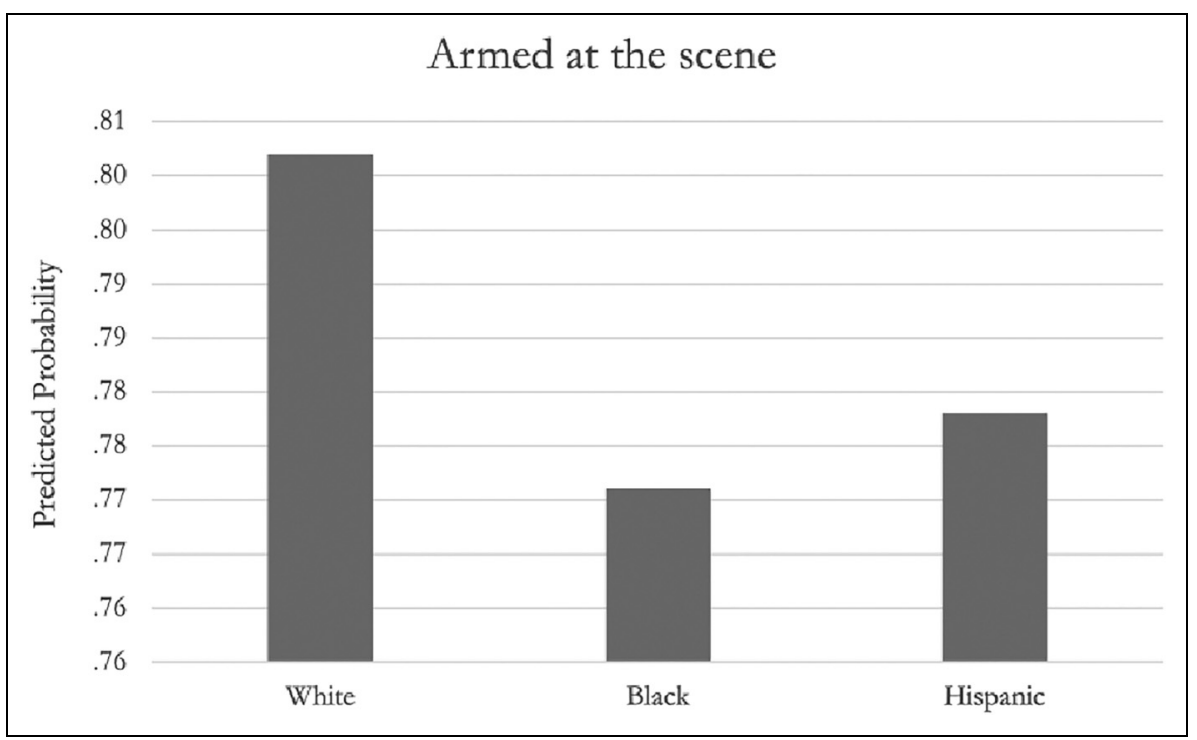

Figure 2. Race-specific marginal probabilities of victims being armed during fatal police encounters: mapping police violence database, 20I3-202I.

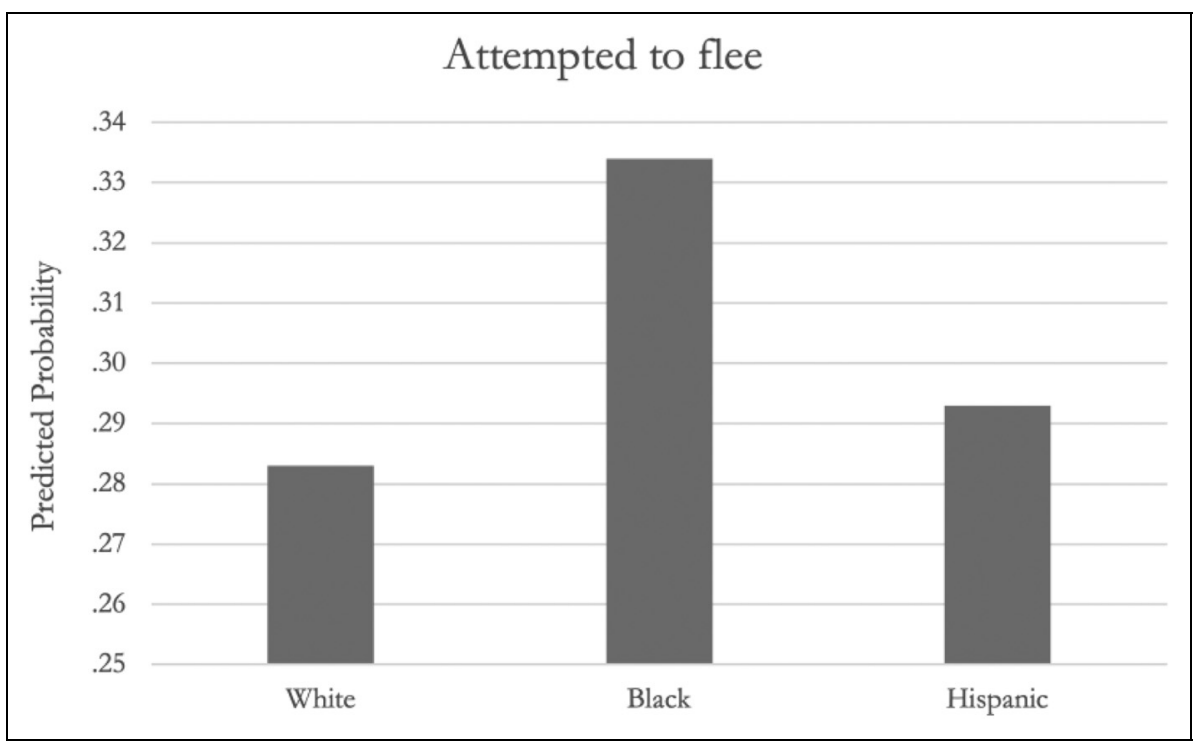

Figure 3. Race-specific marginal probabilities of victims attempting to flee during fatal police encounters: mapping police violence database, 2013-202I. 
White victims have an $80 \%$ predicted probability of being armed, while Black and Hispanic victims have respective probabilities of $77 \%$ and $78 \%$. Finally, Figure 3 shows that Black victims have the highest average probability of fleeing the scene at $33 \%$, followed by Hispanic (29\%) and White (28\%) victims.

\section{Conclusion}

In a nationwide database of police killings between 2013 and 2021, I found that Black victims of police killings were overrepresented, and their White peers underrepresented, relative to the general US population. I also found that Black victims were less likely than their White peers to exhibit signs of mental illness or be armed at the scene of their killings, and more likely to flee the scene. Hispanics were less likely than Whites to exhibit signs of mental illness, but no more or less likely to be armed or flee. All the above patterns persisted even after accounting for heterogeneity by state, zip code, and neighborhood type in which fatal encounters occurred.

This study provides rigorous and compelling evidence of systemic racism in police killings across the United States. Data for this study encompassed all 50 states and the Washington, D.C. area; over 4,000 five-digit zip codes; and a mix of suburban, urban, and rural neighborhoods. Despite such geographic heterogeneity, White victims appeared to pose greater threats to the safety of police officers than Black or Hispanic victims, yet also were underrepresented in police killings relative to the general US population. Put another way, the threshold for being perceived as dangerous, and thereby falling victim to lethal police force, appears to be higher for White civilians relative to their Black or Hispanic peers. These findings are consistent with the notion of systemic pro-White/anti-Black racism in policing nationwide.

This study has broader implications for policing, policymaking, and public health. First, current findings are supportive of campaigns to diversify and retrain police officers in efforts to curb racial disparities in the use of lethal police force. For example, other studies have found that Black and Hispanic officers tend to use less force and make fewer stops or arrests, relative to their White peers, especially in majority-Black or Hispanic neighborhoods (Ba et al., 2021; Legewie \& Fagan, 2016). The present study suggests that Black and Hispanic officers may be more understanding of the skepticism and fear that POC civilians express toward police officers, given the racist legacies of policing in our country (Alexander, 2010; Gruber, 2021). Thus, police officers - especially White officers - should be better trained on how to anticipate and manage, without lethal force, Black and Hispanic civilians who express hostility or trepidation toward them.

Policymakers will also benefit from knowing that political initiatives aimed at curbing the use of lethal police force could help to address racial disparities in deaths by police, and may even help to mitigate broader health disparities in the United States. For instance, Black Americans-and especially Black men-have long been known to live shorter and sicker lives than their White peers (Hummer \& Hamilton, 2019). Recent studies also indicate that recurring fears of police victimization represent major chronic stressors in the lives of Black Americans, particularly 
Black men (Bor et al., 2018; Curtis et al., 2021; McLeod et al., 2020; Sewell et al., 2016). This study suggests that redressing systemic racism in policing could conceivably reduce chronic stress burdens and improve health among Black men, who are still disproportionately targeted by police nationwide.

This brief research note provides new evidence consistent with systemic anti-Black racism in police killings across the United States. Future studies should replicate and extend these findings as more data on police violence become available.

\section{Acknowledgements}

Reed DeAngelis received support from the Population Research Infrastructure Program (P2C-HD050924) and the Biosocial Training Program (T32-HD091058) awarded to the Carolina Population Center at the University of North Carolina at Chapel Hill by the Eunice Kennedy Shriver National Institute of Child Health and Human Development.

\section{Declaration of Conflicting Interests}

The author(s) declared no potential conflicts of interest with respect to the research, authorship, and/or publication of this article.

\section{Funding}

The author(s) disclosed receipt of the following financial support for the research, authorship, and/or publication of this article: This work was supported by the Eunice Kennedy Shriver National Institute of Child Health and Human Development (grant number P2C-HD050924, T32-HD091058).

\section{ORCID iD}

Reed T. DeAngelis (iD https://orcid.org/0000-0002-6471-9802

\section{References}

Alexander, M. (2010). The New Jim crow: Mass incarceration in the Age of colorblindness. The New Press.

Ba, B. A., Knox, D., Mummolo, J., \& Rivera, R. (2021). The role of officer race and gender in police-civilian interactions in Chicago. Science, 371(6530), 696-702.

Bor, J., Venkataramani, A. S., Williams, D. R., \& Tsai, A. C. (2018). Police killings and their spillover effects on the mental health of black Americans: A population-based, quasi-experimental study. The Lancet, 392(10144), 302-310.

Curtis, D. S., Washburn, T., Lee, H., Smith, K. R., Kim, J., Martz, C. D., Kramer, M. R., \& Chae, D. H. (2021). Highly public anti-black violence is associated with poor mental health days for black Americans. Proceedings of the National Academy of Sciences, 118(17), e2019624118.

Fagan, J. A., \& Campbell, A. D. (2020). Race and reasonableness in police killings. Boston University Law Review, 100, 951-1016.

Gee, G. C., \& Hicken, M. T. (2021). Commentary - structural racism: The rules and relations of inequity. Ethnicity \& Disease, 31(Supplement 1), 293-300.

Gruber, A. (2021). Policing and "bluelining". Houston Law Review, 58, 867-936. 
Hummer, R. A., \& Hamilton, E. R. (2019). Population health in america. University of California Press.

Legewie, J., \& Fagan, J. (2016). Group Threat, Police Officer Diversity, and the Deadly Use of Police Force. Columbia Public Law Research Paper No. 14-512.

Mcleod, M. N., Heller, D., Manze, M. G., \& Echeverria, S. E. (2020). Police interactions and the mental health of Black Americans: A systematic review. Journal of Racial and Ethnic Health Disparities, 7(1), 10-27.

Morabito, M., \& Shelley, T. O. (2015). Representative bureaucracy: Understanding the correlates of the lagging progress of diversity in policing. Race \& Justice, 5(4), 330-355.

Phelan, J. C., \& Link, B. G. (2015). Is racism a fundamental cause of inequalities in health? Annual Review of Sociology, 41(1), 311-330.

Raudenbush, S. W., \& Bryk, A. S. (2002). Hierarchical linear models: Applications and data analysis methods (Vol. 1). Sage.

Rothstein, R. (2017). The color of law: A forgotten history of how our government segregated America. Liveright Publishing.

Sewell, W., Horsford, C. E., Coleman, K., \& Watkins, C. S. (2016). Vile vigilance: An integrated theoretical framework for understanding the state of black surveillance. Journal of Human Behavior in the Social Environment, 26(3-4), 287-302.

Sinyangwe, S., McKesson, D., \& Elzie, J. (2021, March 31). Mapping Police Violence Database. https://mappingpoliceviolence.org/.

Thomas, M. D., Jewell, N. P., \& Allen, A. M. (2021). Black and unarmed: Statistical interaction between Age, perceived mental illness, and geographic region among males fatally shot by police using case-only design. Annals of Epidemiology, 53, 42-49.

US Census Bureau (2021, August 12). Race and Ethnicity in the United States: 2010 Census and 2020 Census. https://www.census.gov/library/visualizations/interactive/race-and-ethnicityin-the-united-state-2010-and-2020-census.html.

Van Cleve, N. G. (2016). Crook county: Racism and injustice in America's Largest criminal court. Stanford University Press.

Woods, J. (2019). Policing, danger narratives, and routine traffic stops. Michigan Law Review, $117(4), 635$. 